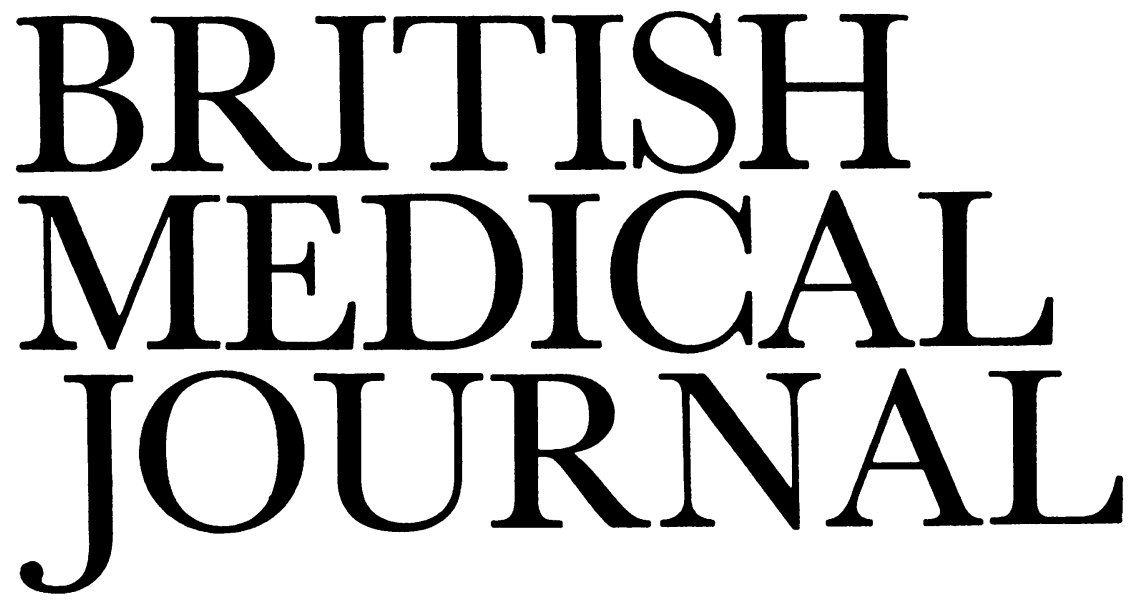

\title{
International Health Regulations
}

New International Health Regulations now in force were adopted by the World Health Assembly in May 1970. They bring up to date the procedures considered necessary to minimize the risk of spread of disease by international trade and travel and replace the International Sanitary Regulations which had been in force since 1 October 1952.

The need for revision resulted from advances in epidemiological knowledge, and the need to cope with changes in the world patterns of trade and travel. The increasing use of containers and other forms of unit loads has radically changed the handling of cargo, with the possibility that vectors and infected cargoes may be imported without the close port check of former years. Moreover, the speed and volume of international travel have developed on an unprecedented scale, and all the indications are for even vaster developments in the future. For instance, the number of passengers carried on international air journeys increased from 7 million in 1951 to 50 million in 1966, and this figure must be further increased to account for journeys by the large passenger aircraft now being brought into service. Co-operative international action has led to mass campaigns for the control of such diseases as malaria, smallpox, and poliomyelitis, and these control measures have also had an impact on the risks of the spread of disease from one country to another.

Under the existing conditions the aim of the new regulations is to ensure maximum security against the international spread of disease with the minimum interference with world traffic. To achieve this the philosophy of international health control has undergone a radical change. Formerly much reliance was placed on international declarations of health and medical inspection of the ship, aircraft, and the passengers if considered necessary at the port of arrival. The new approach places its main emphasis on epidemiological intelligence or international disease surveillance. This requires that all of the World Health Organization's 131 member and associate member States disclose immediately the presence of any serious infectious disease within their borders, so that this information can be available on a worldwide scale. Armed with this information ports and airports can carry out any reasonable measures to prevent the import of disease. Unfortunately countries vary widely in their views on what are reasonable measures, as the excessive restrictions applied by several countries in the recent cholera outbreak have shown. Health control measures should be based on epidemiological knowledge and not imposed as political placebos.

These regulations have been given the force of law in Britain by the Public Health (Ships) Regulations 1970 and the Public Health (Aircraft) Regulations 1970.1 While they are largely the concern of public health officers, there are a number of general points of considerable importance. Doctors will also find valuable information in the Department of Health's pamphlet, Notice to Travellers-Health Protection, which gives authentic information on requirements for foreign travel.

The International Certificate of Vaccination has been slightly modified, but the changes do not affect the validity $\mathrm{cf}$ the existing ones for the period for which they are issued. The certificate requires the personal signature of a medical practitioner; his official stamp is not accepted as a substitute nor is the signature of the clinic nurse. The correct procedure is for the doctor to do the vaccination himself and sign the certificate as the vaccinator. On all international vaccination certificates the manufacturer of the vaccine as well as the batch number must now be given.

The six classic quarantinable diseases under the old regulations-namely, plague, cholera, smallpox, yellow fever, louse-borne typhus, and relapsing fever-have been reduced to four. The last two, typhus and relapsing fever, are no longer considered a threat to international health. At the same time, with the ever increasing speed and volume of international travel, other diseases such as malaria, typhoid fever, poliomyelitis, and influenza, must now form part of the international surveillance of W.H.O. so that information can rapidly be available to national health administrations. It is worth emphasizing that the expanding package-holiday market to tropical countries with underdeveloped hygienic standards greatly increases the risks. For the doctor seeing a patient the need to ask the question, "In the past six months have you made any journeys abroad?" is more essential than ever before. The first effective point of control in Britain of a disease acquired abroad is now likely to be when the ill patient consults his family doctor. 